\title{
FAMILIAL ATAXIA, DEAF-MUTISM, AND MUSCULAR WASTING
}

\author{
BY \\ W. B. MATTHEWS \\ From the University Department of Neurology at the Manchester Royal Infirmary
}

The hereditary disorders of the nervous system are classically presented in eponymous compartments, but it has long been apparent that strict subdivision is difficult to maintain. The affected members of the family reported here presented, in the fully developed syndrome, signs of cerebellar dysfunction, affection of the posterior and lateral columns of the spinal cord, deaf-mutism, and selective muscular wasting. The distribution of the affected members can be seen from the accompanying pedigree.

\section{Case Reports}

II.3 (No. 130551), a joiner's assistant, aged 39, was admitted to the Manchester Royal Infirmary under the care of Dr. F. R. Ferguson in September, 1949, and was the member of the family examined in greatest detail. The history of his disease was compiled from the patient and from other members of his family. He was the third child and was thought to have been normal at birth. He was backward in learning to speak, but it was not until the age of 5 that his parents noticed that he was deaf. It is now impossible to discover whether he was born deaf, but in view of his comparatively well articulated speech in adult life it seems unlikely, However from early childhood he was, for practical purposes, completely deaf, and attended a special school where he learnt to lip-read.

The onset of further symptoms was variously dated by the patient and his family, but one of his brothers thought that at about the age of 15 the patient's walking became unsteady and slowly deteriorated. The patient denied any such symptoms until the age of 35 when his legs rapidly became weak "above the knees". This weakness progressed so that for 10 months before admission he had been unable to work.

He first attended hospital in September, 1948, with synovitis of the right knee, and at that time wasting of the quadriceps was noted. He continued to attend the orthopaedic clinic, and eventually fasciculation was seen in the wasted quadriceps and he was referred for neurological opinion.

He was a pleasant and cooperative patient who could lip-read with some skill and was adept at understanding gesture. There was no obvious defect of intelligence and he was emotionally stable. His speech was monotonous in pitch and accompanied by sibilant expiratory sounds, but was seldom unintelligible.

F
On physical examination no abnormality could be found in the heart, lungs, or abdomen. The blood pressure was $140 / 80 \mathrm{~mm}$. Hg. There was no scoliosis, and no deformity of the feet.

The sense of smell was intact.

The optic fundi were normal and the acuity was $6 / 6$ and $\mathrm{J} 1$ in both eyes. The visual fields were full. The ocular movements were normal and there was no nystagmus. The pupils were regular and equal with normal reflex activity.

There was no impairment of sensation over the face. The temporal fossae appeared unduly hollow, but there was no detectable weakness of the masticatory muscles. The jaw-jerk was brisk. There was no facial weakness, and the palate and tongue moved normally.

For practical purposes he was completely deaf. More exact testing (Dr. Purcer Smith) showed gross bilateral nerve deafness, with some residual hearing above 512 cycles, and a little residue below this pitch at 10-20 decibels. The ear-drums were normal. There was full vestibular response to rotation, but moderate reduction of response to caloric stimulation on the left side only.

There was evident muscular wasting in all limbs (Fig. 1). In the arms the wasting was slight and peripheral in distribution, being most marked in the hands, but in the legs the weakness and wasting were maximal above the knees, particularly in the quadriceps muscles. The calves were abnormally thin and the power of the tibialis anterior was reduced on both sides, but there was no detectable weakness of the peronei or gastrocnemii. The selective distribution of the wasting may be seen from the following measurements :

Maximum circumference of calves $31 \mathrm{~cm} . \quad 31 \cdot 5 \mathrm{~cm}$. Circumference of thighs $10 \mathrm{~cm}$.

above upper border of patella $29.5 \mathrm{~cm} .30 \mathrm{~cm}$.

When first seen one of the most striking features of his condition was the pronounced fasciculation of the wasted muscles of the thighs, but this became less obvious on subsequent examinations, and appeared to be of the nature of "contraction fasciculation" as it was never seen in fully relaxed muscles. When present it consisted of rapif fine, flickering contractions evenly distributed throughout the affected muscle. All muscles responded to faradism.

The tendon reflexes in the arms were uniformly exaggerated, but Hoffman's sign could not be elicited. The knee jerks were diminished and the ankle jerks 

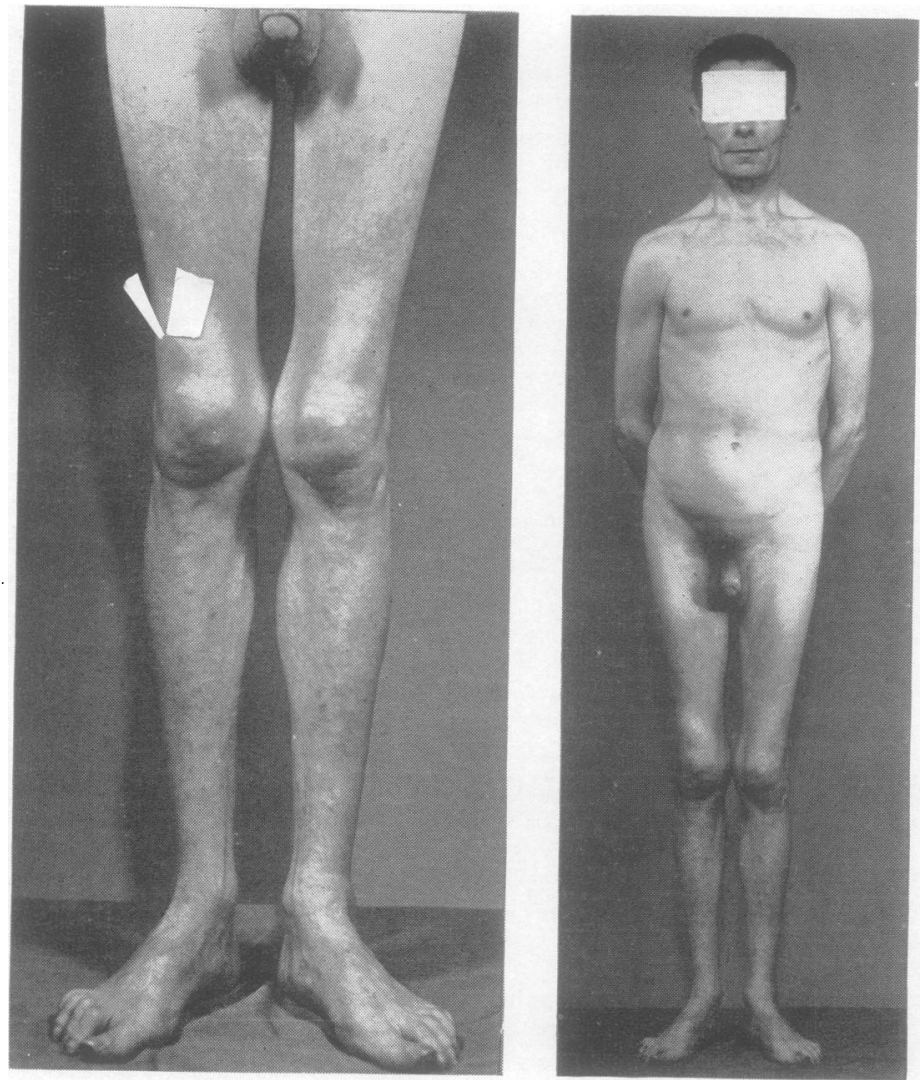

absent. The abdominal reflexes were present, but both plantar reflexes were extensor.

Sensation was intact except in the legs. Postural sense was impaired in the toes of both feet, and vibration sense was absent in the left foot. There was no impairment of cutaneous sensation.

There was marked cerebellar ataxia in all limbs. Alternating movements were poorly performed, and his writing was shaky and uncertain. His gait was slow, but he was less incapacitated than might have been supposed. The feet were set down wider apart than normal, and at each step the heel caught the ground as the advancing leg passed the horizontal. The foot was then swung clear of the ground again and brought down with abnormal force. This unusual gait appeared to be due in part to his lack of confidence in the power of the quadriceps to support his weight with the knee even slightly flexed.

Further investigation did not add anything of importance. There was no anaemia and the leucocyte count was normal. The cerebrospinal fluid contained 1 lymphocyte per c.mm. and 400 $\mathrm{mg}$. of protein per $100 \mathrm{ml}$. The Wasser mann reaction was negative in blood $\overline{\mathbb{Q}}$ and cerebrospinal fluid. The electrocardiograph was within normal limits. A 24-hour specimen of urine containedo no creatine and $1.4 \mathrm{~g}$. of creatinine. Radiographs of

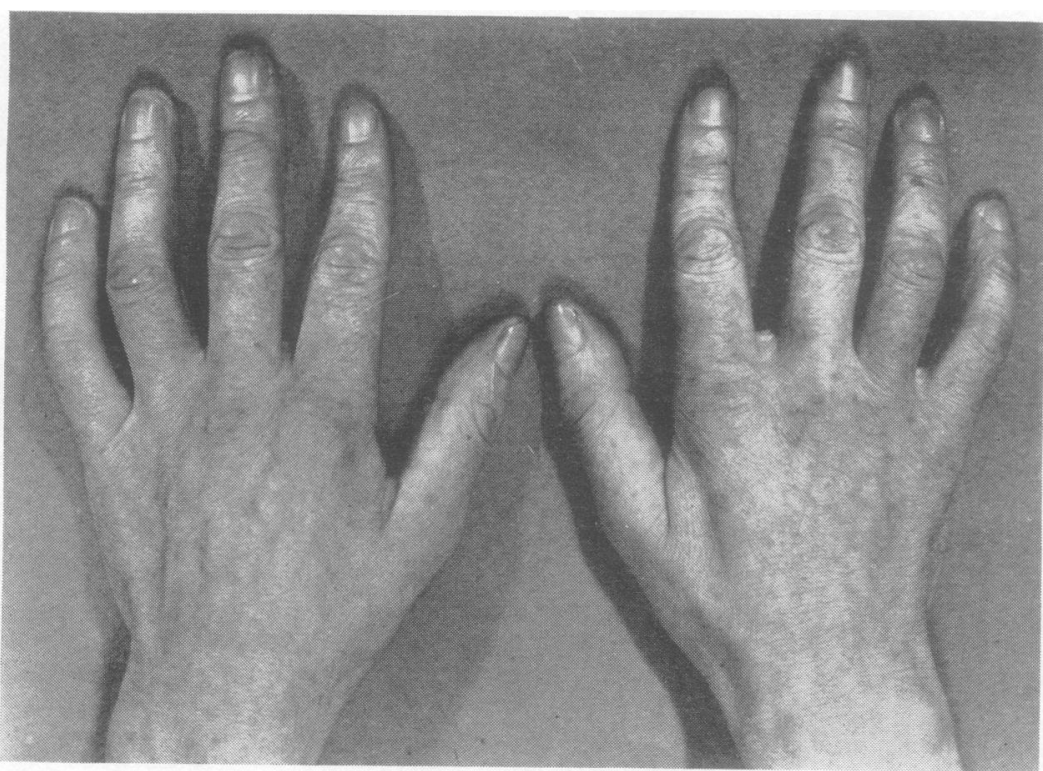

FIG. 1.-Distribution of muscular wasting in Case II.3. the spine and skull were normal.

I.1, the father of II.3, aged 69 , had been healthy until incapacitated by silicosis. He was examined, and apart from his respiratory condition, no abnormality was found. In particular his hearing was normal, and there was no ataxia or muscular wasting. He stated that his three brothers and two sisters had been similarly normal, and that his parents had been healthy, his mother having recently died at the age of 100 .

I.2, the mother of II.3, aged 71 , had been healthy apart from an abscess behind the left eye at the age of 30 which had left her with a "small eye". On examination there was ptosis of the left upper eyelid, but no other abnormality 
of the nervous system could be found, except that both ankle jerks were somewhat sluggish. Hearing was normal and there was no muscular wasting. She stated that her parents and four sisters had been healthy. She was not related to her husband.

II.1, the eldest child of I.1 and I.2, a man of 44, was examined and found to be normal.

II.2, a man aged 42, had never learnt to speak intelligibly and had probably been deaf from birth. Soon after leaving school his gait was noticed to be slow and unsteady, but he was not seriously affected until the age of 33 when his disabilities began to be incapacitating, and since that time he had steadily deteriorated.

He was much less skilled at lip-reading than II.3, and his speech was more severely affected, being, in fact, unintelligible. The optic fundi were normal, and there was no nystagmus. He was severely deaf, but this was not analysed in detail. The ear-drums were normal.

There was severe wasting of the intrinsic muscles of the hands and of the lower halves of the forearms, and, in addition, some weakness of the proximal muscles of the arms without obvious wasting. The quadriceps muscles were profoundly wasted, particularly in the lower two-thirds. The calves were abnormally thin but were not so severely affected as the muscles above the knees. No fasciculation was seen. The tendon reflexes in the arms were uniformly exaggerated; the knee jerks were diminished and the ankle jerks absent. The abdominal reflexes were present and both plantar reflexes were extensor. There was no intention tremor of the arms, but alternating movements were poorly performed. There was gross incoordination of the legs. His gait was similar to that of JI.3, but more ataxic. Vibration sense and sense of passive movement were impaired in both feet.

II.4, a woman aged 36, and II.5, a man aged 34, were examined and found to be normal.
II.6, a man aged 32, had been healthy until the age of 15 , when, following an attack of otorrhoea, he was found to have perforated ear-drums, and since that time he had been moderately deaf. Apart from his deafness he was thought to be normal, and examination had, therefore, to be unduly rapid, as it was not thought desirable to draw attention to the abnormalities discovered. He was found to have a moderately severe conductive deafness, and both ear-drums were scarred and opaque. Speech was normal, and no other abnormality could be discovered in the cranial nerves. However, there was evident wasting of the thenar muscles and marked wasting of the quadriceps, but apparently none below the knees. The tendon reflexes in the arms were increased, the knee jerks diminished, and the ankle jerks absent. Both plantar reflexes were extensor. No incoordination or sensory loss could be demonstrated.

II.7, a man aged 30, had been deaf from birth and had never spoken intelligibly, but was otherwise thought to be normal. On examination he was severely deaf and the ear-drums were normal. His speech was unintelligible, but no other abnormality could be discovered in the cranial nerves. There was no wasting in the arms or calves, but there was distinct wasting of both quadriceps. The tendon reflexes were brisk in the arms, the knee jerks were diminished and the ankle jerks absent. Both plantars were extensor. There was no incoordination or sensory loss.

III.1, a man, aged 20, the eldest child of II.1, was not examined, but was stated to be normal.

III. 2, 3, and 4, daughters of II.1, aged 18, 15, and 13, were examined and found to be normal.

III.5, a boy, aged 12, the elder child of II.3, was not examined but was stated to be normal.

III.6, a boy, aged 7, the second child of 11.3, was examined and found to be normal.

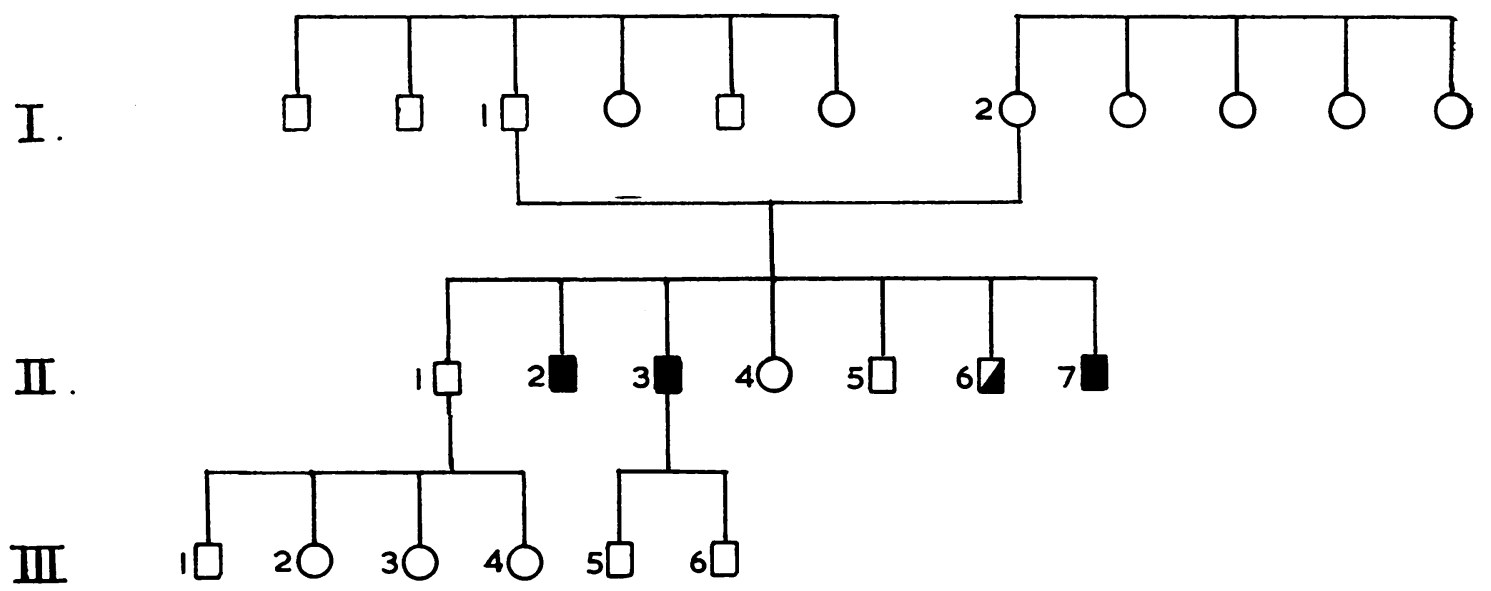

$=$ Deaf-mute, with signs of spinal cord affection and muscular wasting. $=$ Spinal cord affection, muscular wasting and exogenous deafness.

FIG. 2.-Pedigree of affected family. 


\section{Discussion}

The four affected members (Fig. 2) of this family present the features of a familial disorder reminiscent of Friedreich's ataxia, without pes cavus or scoliosis, but with the addition of deaf-mutism in three and of selective muscular wasting in all. The existence of acquired deafness in the fourth case is interesting but probably only coincidental, as no clear predisposition to exogenous deafness can be demonstrated in those with a hereditary taint of deafmutism (Lindenov, 1945).

Hammerschlag (1932) drew a rather laborious parallel between the Japanese waltzing mouse, which suffers from hereditary deafness, albinism, ocular defects and ataxia, and the human deafmute. He postulated a heredopathia acousticooptico-cerebro-spinalis, the factors being transmitted by linked recessive genes. The association between deaf-mutism and retinitis pigmentosa is well attested (Bell, 1922), and mental deficiency probably occurs more frequently than in the general population. Hammerschlag was, however, only able to describe two cases of ataxia associated with hearing defect. In one, ataxia of the Friedreich type was combined with deaf-mutism, partial albinism, mental deficiency, and a variety of developmental defects. The second case presented a combination of retinitis pigmentosa, nerve deafness of comparatively late onset, and an ataxic gait. No detailed examination of the nervous system was recorded.

The hypothesis of a linked inheritance of deafmutism and ataxia receives little support from a study of the literature of Friedreich's ataxia, as, despite the great variety of neural and extra-neural anomalies found sporadically in this condition, deafness is uncommon, and deaf-mutism extremely rare. Thomas and Roux (1901) reported a case of ataxia of unusual type combined with deafness, the auditory condition not being described in detail, and Variot and Bonniot (1907) described a girl with cerebellar ataxia and progressive nerve deafness beginning at the age of ten. In neither of these cases was there any apparent hereditary factor, but Koennecke (1919) reported a brother and sister with progressive nerve deafness from an early age combined with Friedreich's ataxia and generalized muscular atrophy. Clauss (1924) described a case of ataxia of the Marie type with retinitis pigmentosa and a moderate degree of nerve deafness.

Muscular wasting has frequently been described in Friedreich's ataxia. In many of the reports (for example, those of Rook and Dana, 1890; Whyte, 1898) the wasting has not been selective but an atrophy of the limb musculature late in the disease and possibly due to disuse. However, a great variety of more distinct forms has been described, ranging from wasting of the intrinsic hand muscles (Hodge, 1897) to extensive myopathy with pseudohypertrophy (Spiller, 1910). Spiller's case came to necropsy, and it was clearly shown that both neurogenic and myopathic atrophy occurred in the same patient. The precise form of atrophy present in the family reported here does not appear to have been described in association with ataxia. Although there are some similarities with peroneal muscular atrophy, there can be no doubt that the wasting first developed above the knees, and that the main disability was due to the consequent instability of the knee joints, and not to weakness round the ankle joints, as in the classical condition.

The association between Friedreich's ataxia and peroneal muscular atrophy is of particular importance with regard to the general question of the inheritance of disease of the nervous system. The coexistence of the two conditions in the same patient has been described by Greenfield (1912), and Fearnsides (1912), and Spillane (1940) reported a family in which there was one case of Friedreich's ataxia and three of peroneal muscular atrophy, as well as many of the syndrome of pes cavus and absent ankle jerks, which might be regarded as abortive cases of either condition. Roth (1948) recently described two families in which the two conditions coexisted, and discussed the mode of inheritance. He concluded that the gene conveying the combined syndrome was probably distinct from those transmitting the individual diseases. The inheritance in the present family might be explained by the existence of two or three recessive genes, three siblings being homozygous for ataxia, muscular wasting, and deaf-mutism, and the fourth for the two former only. It is statistically much more probable that a single recessive gene transmitted all three conditions, with lack of penetrance for deaf-mutism in one case. The exact probability cannot be stated as the factor for lack of penetrance cannot be determined on so small a pedigree.

In spite of great variety in detail the hereditary diseases of the nervous system tend to be curiously stereotyped in general outline, and the more aberrant forms can often be interpreted as combinations of well recognized syndromes. It is also known that clinical syndromes distinguishable only by time of onset may be transmitted by different genes, or at least by differently situated genes. Thus, for example, peroneal muscular atrophy is known in dominant, recessive, and sex-linked forms (Bell, 1935), which must imply that this condition may be transmitted by a gene either on the $\mathrm{x}$-chromosome or on an autosome. In view of the structural 
complexity of the nervous system the comparatively restricted range of manifestations of hereditary disease is surprising. The coexistence of two or more of these manifestations in the same pedigree is well-known, and has given rise to the conception of a " neuropathic heredity" on a rather ill defined genetic basis. The pedigree of Friedreich's ataxia reported by Franceschetti and Klein (1941) is of interest here. In one offshoot the ataxia was apparently replaced by labyrinthine hardness of hearing, and in another by retinitis pigmentosa. These two conditions were regarded as " equivalent " to Friedreich's ataxia, and transmitted by the same gene. The means by which the genes exert their profound influence on the soma are largely unknown, but must be fundamentally biochemical. A neuropathic heredity might be explained by a very limited range of genetically influenced metabolic aberrations. The clinical results of such aberrations would in part depend on the stage at which the developing nervous system was exposed, which, in turn, might well be modified by the influence of the total genetic structure on the abnormal gene. Any such explanation must remain entirely speculative, as the nature of the genetically determined lesion that can produce, often after a long latent period, degeneration of formerly normally functioning neurones, remains quite obscure.

\section{Summary}

A family is reported in which four members of a sibship of seven developed a condition similar to Friedreich's ataxia accompanied by muscular wasting of unusual distribution. Three of the affected members were deaf-mutes.

The literature is reviewed and some speculations offered on the mode of inheritance.

I am indebted to Dr. Fergus R. Ferguson for permission to report on Case II.3, and to Dr. C. R. W. Gray for permission to examine other members of the family : to Dr. H. C. Purcer Smith for his report on the aural condition of Case II.3 ; and to Dr. M. D. Milne for advice on statistics.

\section{REFERENCES}

Bell, J. (1922). Treas. hum. Inher., 2, 17. (1935). Ibid., 4, 91.

Clauss, O. (1924). Z. ges. Neurol. Psychiat., 93, 294.

Fearnsides E. G. (1912). Proc. R. Soc. Med., 5, Neurol. Sect., p. 144.

Franceschetti, A., and Klein, D. (1941). Arch. KlausStift. Vererb-Forsch., 16, 469.

Greenfield, J. G. (1912). Proc. R. Soc. Med., 5, Neurol. Sect., p. 75.

Hammerschlag, V. (1932). Wien. klin. Wschr., 45, 772, 808.

Hodge, G. (1897). Brit. med. J., 1, 1405.

Koennecke, W. (1919). Z. ges. Neurol. Psychiat., 53, 161.

Lindenov, H. (1945). " The Etiology of Deaf-mutism with Special Reference to Heredity." Copenhagen.

Rook, C. W., and Dana, C. L. (1890). J. nerv. ment. Dis., 17, 173.

Roth, M. (1948). Brain, 71, 416.

Spillane, J. D. (1940). Ibid., 63, 275.

Spiller, W. G. (1910). J. nerv. ment. Dis., 37, 411.

Thomas, A., and Roux, J. C. (1901). Rev. Méd., 21, 762.

Variot, G., and Bonniot, E. (1907). Rev. neurol., 15, 298.

Whyte, J. M. (1898). Brain, 21, 72. 